\title{
A MÚSICA E SEUS BENEFÍCIOS PARA O DESENVOLVIMENTO SAUDÁVEL NA INFÂNCIA
}

\author{
Jeane Barros de Souza \\ Universidade Federal da Fronteira Sul \\ jeanebarros18@gmail.com \\ Ângela Urio \\ Universidade Federal da Fronteira Sul \\ ange.urio@hotmail.com \\ Simone dos Santos Pereira Barbosa \\ Universidade Federal da Fronteira Sul \\ mone.96@hotmail.com
}

\author{
Lisiane da Rosa \\ Universidade Comunitária Regional de Chapecó \\ rosa.lisiane@gmail.com \\ Tatiana Xirello \\ Universidade Federal da Fronteira Sul \\ taty-xirello@hotmail.com \\ Angélica Zanettini \\ Universidade de Passo Fundo \\ gelyzanettini@hotmail.com \\ Emanuelly Luize Martins \\ Universidade Federal da Fronteira Sul \\ emanuelly_martins@hotmail.com
}

\begin{abstract}
Resumo
Objetivo: compreender a percepção das crianças, participantes do canto coral, sobre a utilização da música como instrumento de promoção da saúde. Método: estudo descritivo, com abordagem qualitativa, realizado com 12 crianças integrantes de um coral, de um projeto de extensão do Curso de Enfermagem, da Universidade Federal da Fronteira Sul, Chapecó-SC. A coleta dos dados foi por meio do grupo focal no ano 2017, utilizando análise de conteúdo para analisar e interpretar os dados. Resultados: As crianças acreditam que a prática do canto coral proporciona diversão, momentos de lazer e cultura, sendo também uma forma de vencer seus medos e a timidez. Para elas, a música proporciona alegria, diversão, saúde, integração, descoberta de novas amizades, sendo um dos motivos que as fazem frequentar as atividades do coral. Conclusão: além dos benefícios terapêuticos, a música é um recurso para promover a saúde, metodologia diferenciada e inclusiva, que gera uma infância saudável.

Palavras-chave: Música. Saúde da Criança. Promoção de Saúde. Enfermagem.
\end{abstract}

\section{MUSIC AND ITS BENEFITS FOR HEALTHY DEVELOPMENT IN CHILDREN}

\section{Abstract}

Objective: To understand the perception of children, participants of choral singing, about the use of music as a health promotion instrument. Method: a descriptive study with a qualitative approach, conducted with 12 children from a choir, from an extension project of the Nursing Course, Federal University of Fronteira Sul, Chapecó-SC. Data collection was through the focus group in 2017, using content analysis to analyze and interpret the data. Results: Children believe that the practice of choral singing provides fun, moments of leisure and culture, as well as a way to overcome their fears and shyness. For them, music provides joy, fun, health, integration, discovery of new friendships, being one of the reasons that make them frequent the activities of the choir. Conclusion: In addition to the therapeutic benefits, music is a resource to promote health, a differentiated and inclusive methodology that generates a healthy childhood.

Keywords: Music. Child Health. Health Promotion. Nursing.

\section{LA MÚSICA Y SUS BENEFICIOS PARA EL DESARROLLO SALUDABLE EN LA INFANCIA}

\section{Resumen}

Objetivo: Comprender la percepción de los niños, participantes del canto coral, sobre el uso de la música como instrumento de promoción de la salud. Método: estudio descriptivo con enfoque cualitativo, realizado con 12 niños de un coro, de un proyecto de extensión del Curso de Enfermería, Universidad Federal de Fronteira Sul, Chapecó-SC. La recopilación de datos se realizó a través del grupo focal en 2017, utilizando el análisis de contenido para analizar e interpretar los datos. Resultados: Los niños creen que la práctica del canto coral proporciona diversión, momentos de ocio y cultura, así como una forma de superar sus miedos y timidez. Para ellos, la música les brinda alegría, diversión, salud, integración, descubrimiento de nuevas amistades, siendo una de las razones que les hacen frecuentar las actividades del coro. Conclusión: además de los beneficios terapéuticos, la música es un recurso para promover la salud, una metodología diferenciada e inclusiva que genera una infancia saludable.

Palavras clave: Música. Salud del Niño. Promoción de Salud. Enfermería. 


\section{INTRODUÇÃO}

Nas últimas décadas, o conceito de saúde vem sendo ampliado, e com a implementação do Sistema Único de Saúde (SUS), foram surgindo novas políticas no setor com ênfase em torno da promoção da saúde (ZANETTINI et al., 2015). A promoção da saúde, de acordo com a Carta de Ottawa (1986), é descrita como um seguimento de ações que proporcionam aos indivíduos a capacidade destes melhorarem seu estado de saúde de maneira integral, envolvendo seu físico, mental e social, não somente visualizando a ausência de doença.

Dentre as diversas políticas e práticas organizadas, destaca-se a Política Nacional de Promoção da Saúde (PNPS), que visa implementar ações de promoção através de instruções e instrumentos para a compreensão de se alcançar o estado saudável (BRASIL, 2010), além daquelas voltadas ao público infantil, que necessita ter seu espaço de atenção e assistência em saúde.

Uma das maneiras de promover a saúde na infância é por meio da utilização da música, pois o conhecimento de que a música interfere na saúde e no bem-estar das pessoas já existia no tempo de Aristóteles e Platão. No entanto, somente em meados do século passado foi possível estabelecer, com evidências científicas, uma relação entre a música e a saúde (AREIAS, 2016).

Segundo Taets e Barcellos (2010), a música está presente na Classificação de Intervenções de Enfermagem - Nursing Intervention Classification (NIC) e a sua primeira utilização como forma de cuidado à saúde foram relatadas por Florence Nightingale no século XIX. Além disso, também é evidenciado o uso da música durante a I e II Guerras Mundiais, pelas enfermeiras musicistas norte-americanas Isa MaudIlsen e Harriet Ayer Seymour, no cuidado como recurso terapêutico para alívio da dor física e emocional dos soldados feridos.

A intervenção musical contribui significativamente para o alívio da ansiedade, do estresse e para a promoção do relaxamento, além de ser importante para crianças com tendência ao isolamento social (FINGER et al., 2015). Ainda conforme as autoras, a música é uma ferramenta que pode e deve ser utilizada de forma interdisciplinar para promover a saúde na infância, pois não é só um meio de lazer, mas atua também no desenvolvimento físico, intelectual e participativo.

A música é um recurso importante para atuar com as crianças no mundo contemporâneo, em que a tecnologia está inserida de maneira intensa, perdendo-se por vezes a interação e o convívio com o outro. Desta forma, é válido considerar que, além dos benefícios 
sociais e culturais, a música pode ser utilizada para promover a saúde física e mental na infância, contribuindo para o desenvolvimento integral e saudável (ZANETTINI et al., 2015).

Entre as diversas possibilidades de utilização da música, pode-se citar o canto coral como um veículo de disseminação dos seus benefícios, tais como: maior socialização, trabalho em equipe, perda da timidez, auxílio na organização e sincronia no trabalho, na comunicação, concentração e autoconfiança (CARMINATI; KRUG, 2010). O canto coral é uma prática extremamente interessante, capaz de proporcionar diversos efeitos positivos na qualidade de vida dos envolvidos, como bem-estar psicológico, fortalecimento da autoestima e convívio social (PRAZERES et al., 2013).

Diante dos benefícios que o canto coral proporciona, em 2014 foi organizado um projeto de extensão do Curso de Enfermagem, da Universidade Federal da Fronteira Sul UFFS, campus Chapecó, com o intuito de promover a saúde de crianças e adolescentes através do canto coral. O projeto foi desenvolvido em uma escola pública, localizada em uma comunidade carente em aspectos sociais, econômicos e culturais. Assim, a equipe do projeto de extensão organizou um coral infanto-juvenil, com ensaios semanais no próprio espaço escolar, com a participação dos alunos de maneira espontânea, sendo todos convidados no início de cada ano letivo. O projeto de extensão permaneceu durante quatro anos, de 2014 a 2018, contando com a participação de aproximadamente 45 crianças e adolescentes a cada ano.

Nesta perspectiva, buscaram-se evidências científicas sobre o uso da música como promotora da saúde, surgindo assim o projeto de pesquisa denominado "A percepção de crianças e adolescentes sobre a utilização da música como meio de promover a saúde”, do curso de Enfermagem da UFFS. Assim, este estudo tem como objetivo compreender a percepção das crianças, participantes do canto coral, sobre a utilização da música como instrumento de promoção da saúde.

\section{MATERIAIS E MÉTODOS}

Trata-se de um estudo exploratório, descritivo, com abordagem qualitativa, realizado em uma escola pública no município de Chapecó-SC. Tal escola possuía vínculo com a UFFS, por meio da realização de um projeto de extensão, onde foi criado um coral infanto-juvenil, que realizava apresentações culturais no espaço escolar e em programações da universidade e do município e região, com repertório eclético que abordava músicas com temáticas referentes a cidadania, paz, amor, família, fé e amizade. 
O estudo contou com a participação de 12 crianças, que integravam o coral, com idade entre 8 e 10 anos, regularmente matriculadas na escola e frequentadoras assíduas dos ensaios e das apresentações do coral, sendo estes os critérios de inclusão para participar da pesquisa. É importante destacar que os participantes deste estudo residiam em um contexto de vulnerabilidade social, econômica e cultural.

A coleta de dados se deu por meio da utilização do grupo focal (GF), que entre todas as possibilidades metodológicas de uma pesquisa qualitativa, se constitui como uma técnica de coleta que se dá por meio da interação dos participantes de um grupo, promovendo uma ampla problematização do tema em questão (BACKES et al., 2011).

O GF aconteceu na própria escola, no segundo semestre de 2017, em um dia de ensaio do coral, previamente agendado com os responsáveis e com os familiares das crianças, contando com um roteiro de questões norteadoras, envolvendo temáticas sobre a música como promotora da saúde, conceito de saúde e os benefícios que a participação no coral proporciona, com aproximadamente 50 minutos de duração. Para iniciar o GF, primeiramente foi compartilhado um breve vídeo com apresentações do próprio coral, a fim de manter a atenção dos participantes e sensibilizá-los para as temáticas, que passaram a ser discutidas entre as crianças e a equipe de pesquisa.

Antes da realização do GF, foi disponibilizado para as crianças um Termo de Assentimento e para seus respectivos responsáveis o Termo de Consentimento Livre e Esclarecido, mantendo assim afirmado o sigilo das informações e o aceite da participação na pesquisa. Também para manter o anonimato dos participantes, decidiu-se chamá-los por notas musicais.

A pesquisa seguiu a Resolução do Conselho Nacional de Saúde/MS nº 466/2012 e foi desenvolvida pelo curso de graduação em Enfermagem, da UFFS, campus Chapecó-SC, e só iniciou após ser aprovada pelo Comitê de Ética em Pesquisa da UFFS, com parecer número $2.050 .383 / 2017$.

Todas as falas do GF foram gravadas e, posteriormente, transcritas e analisadas a partir da análise de conteúdo, proposta por Bardin (2011), sendo um conjunto de técnicas de análise das comunicações, com intuito de obter, por procedimentos sistemáticos e objetivos de descrição do conteúdo das mensagens, a inferência de conhecimentos relativos às condições de produção/recepção (variáveis inferidas) destas mensagens.

A primeira etapa constituiu-se da pré-análise, onde foi realizada a leitura flutuante dos dados obtidos nas entrevistas, escolhendo documentos para a constituição dos dados tidos em conta para serem submetidos aos procedimentos analíticos. No segundo momento, realizou-se 
A música e seus benefícios para o desenvolvimento saudável na infância

a exploração do material de análise, com a organização dos dados, para construção deste manuscrito, surgindo assim duas categorias: "Promoção da saúde interligada com a música" e "Benefícios do canto coral na infância", que serão apresentadas e discutidas em seguida.

\section{RESULTADOS E ANÁLISES}

\section{Promoção da Saúde interligada com a música}

A promoção da saúde é considerada como um modo de pensar e de operar articulado às demais políticas e tecnologias desenvolvidas no sistema de saúde brasileiro, contribuindo para a construção de ações que possibilitem responder às necessidades sociais em saúde (BEZZERA; SORPRESO, 2016).

As crianças estão vulneráveis a diversas situações e necessitam ter seu espaço de assistência, principalmente na promoção da saúde, pois o direito à saúde é uma prerrogativa constitucional de todo cidadão. Mas afinal, o que as crianças entendem por saúde? Na análise dos depoimentos, observou-se que algumas crianças entendem que saúde é não ficar doente:

Saúde é quando a pessoa está bem, quando ela não tá doente. (Dó)

Saúde é quando o organismo de alguém funciona bem direitinho. (Mi)

Os relatos destes participantes remetem ao antigo conceito de saúde, que era considerado somente a ausência de doenças, mas a partir da I Conferência Internacional sobre Promoção da Saúde, em 1986, na cidade de Ottawa, Canadá, o conceito de saúde foi ampliado considerando o completo bem-estar físico, mental e social (PEREIRA, 2008). É importante destacar que a promoção da saúde está inserida nas relações que os indivíduos criam em seu dia a dia, no meio social, no aprendizado que adquire para seu entendimento e crescimento em relação à saúde, apontando um momento de qualificação sobre seu bem-estar (HEIDMANN et al., 2012).

De acordo com Rodiva et al. (2013), as diferentes visões de saúde se dão pela real conjuntura do que se considera saúde, uma vez que o conceito é o resultado da situação social, econômica e política, e que este mudará dependendo da época em que for visto, do lugar e da classe social. Algumas crianças relacionaram ter saúde com a necessidade de evitar excesso de doces, como se observa nos relatos abaixo:

Saúde é não comer muitos doces [...]. (Si) 
A música e seus benefícios para o desenvolvimento saudável na infância

Saúde para mim é ter uma alimentação saudável, comer vegetais, frutas [...]. (Dó)

O fato é que as preferências alimentares das crianças, conforme Lazari et al. (2012), tendem ao elevado consumo de carboidrato, açúcar, gordura e sal, e um baixo consumo de vegetais e frutas, se comparados às quantidades recomendadas. Esta tendência depende, em grande parte, dos padrões culturais de alimentação do grupo social ao qual ela pertence e a socialização alimentar da criança.

A educação nutricional é conceituada como um processo educativo no qual, através da união de conhecimentos e experiências do educador e do educando, vislumbra-se tornar os sujeitos autônomos e seguros para realizarem suas escolhas alimentares de forma que garantam uma alimentação saudável e prazerosa, propiciando, então, o atendimento de suas necessidades fisiológicas, psicológicas e sociais (LAZARI et al., 2012). No entanto, para alcançar transformação de hábitos alimentares saudáveis, se faz necessário uma enorme mudança que se vincula às práticas e atitudes diárias do indivíduo (BERNART; ZANARDO, 2011).

Outras crianças relacionaram a saúde com o ato de brincar:

Saúde é brincar e se divertir [...]. (Mi)

Ao promover a saúde da criança, o brincar deverá estar presente, pois se percebe que brincando, é possível captar diversos conceitos que a auxilia a entender o universo que a cerca, interagindo com o meio e com as pessoas, o que oportuniza a imaginação, a participação livre e descontraída, dentro do espírito da atividade lúdica. Assim, a música surge como uma brincadeira que transmite alegria, relacionando-se com a criança profundamente e repercute diretamente em seus domicílios e em seus familiares.

As crianças também relacionaram saúde com felicidade e aproveitar a vida:

Ter saúde é aproveitar os momentos bons da vida. (Fá)

Ser feliz também é saúde. (Sol)

No âmbito do conhecimento científico, o termo "felicidade" tem sido traduzido por bem-estar subjetivo, que está fortemente relacionado com a promoção da saúde (COMIN; SANTOS, 2010). Ainda conforme os mesmos autores, a felicidade pode ser definida como a predominância da frequência de ocorrência de experiências emocionais positivas sobre as negativas. A qualidade de vida é subdividida em duas dimensões: bem-estar objetivo, que 
A música e seus benefícios para o desenvolvimento saudável na infância

abarca as circunstâncias objetivas da vida (renda, educação, saúde, lazer, transporte, entre outros domínios) e bem-estar subjetivo, explicitado pelas experiências subjetivas da vida, tendo como objetivo central compreender a avaliação que as pessoas fazem de suas vidas, podendo receber outras denominações, tais como felicidade, satisfação, estado de espírito, afeto positivo, sendo também considerado como avaliação subjetiva da qualidade de vida.

A música interfere positivamente na saúde mental, podendo haver o sentimento de acolhida, escuta atenciosa e o espaço para externalizar emoções, observando ainda a diminuição da agitação e a melhoria do bem-estar psicológico. Ainda, a música promove resultados positivos sobre os níveis de pressão arterial de indivíduos em diferentes situações clínicas, atuando também na diminuição dos níveis de ansiedade, dor e auxiliando no relaxamento (ZANET'TINI et al., 2015). Os relatos a seguir remetem a esta afirmação, quando as crianças interligam a música com a alegria, disposição e saúde:

Acho que a música é importante sim... a gente escuta música e a gente fica mais alegre e com disposição. (Ré)

A música nos torna mais alegre faz a gente ter vontade de cantar, fazer alguma coisa e ser saudável. (Sol)

Quando estou mexendo em alguma coisa e me sinto desanimada, dai eu canto me alegro um pouco mais. (Fá)

Se uma pessoa tiver triste e vê alguém cantando, essa música vai deixar a pessoa feliz. (Si)

Ressalta-se que a música proporciona uma ampla gama de emoções, sendo capaz de excitar ou relaxar, alegrar ou deprimir, motivar ou irritar, e dificilmente, as pessoas ficam indiferentes a uma canção (VENCANIO, 2014). Conforme Areias (2016), o ato de cantar e ouvir música, desperta a liberação de endorfinas neuro-hormonais produzidas na hipófise, que tem uma potente ação analgésica, estimulando a sensação de bem estar, conforto e melhoria de humor.

A música pode atuar como terapia para qualquer tipo de transtorno e muitos fazem isso naturalmente ao ouvir música. De acordo com Vencanio (2014), quando se está deprimido, geralmente se ouve músicas mais tristes e, por outro lado, a tendência é escutar canções mais agitadas para se alegrar. Segundo Oliveira et al. (2014), a música desempenha importante papel na manutenção e melhoria da qualidade de vida, além de propiciar maior interação com o meio social e familiar. 
A música e seus benefícios para o desenvolvimento saudável na infância

Finger et al. (2015), afirmam que além de proporcionar benefícios a quem canta, a música também provoca efeitos positivos na vida e bem-estar de quem ouve, sendo possível extravasar sentimentos e deixar-se envolver, cultivando o bem-estar pessoal, proporcionando uma maior autoestima, promovendo a integração e a convivência com a comunidade e familiares.

\section{Beneficios do Canto Coral na Infância}

São muitos aspectos positivos quando se associa a música ao desenvolvimento da criança, dentre eles os relacionados a habilidades cognitivas, alívio da dor crônica, melhora da qualidade de vida, estímulo ao raciocínio, divertimento, criatividade, expressão de emoções e redução da solidão, além de regular o humor e propiciar interações sociais (PIMENTEL et al., 2012).

Segundo Teliz (2012), a fase da infância é de intensas descobertas e as interações sociais são relevantes e estão ligadas diretamente à aprendizagem de novos comportamentos. As brincadeiras sentidas por meio do canto é uma ação natural da vida infantil, sendo que nestes momentos as crianças podem desenvolver os aspectos físicos, motores, emocionais, sociais e cognitivos, constituindo-se como um importante elemento no processo de crescimento e aprendizagem.

A música é um veículo de movimento entre indivíduos de diferentes gerações e localizações geográficas, representando um potente promotor cultural entre sociedades de épocas e localizações geográficas distintas. Neste sentido, a educação musical deveria representar uma das instâncias mais envolvidas com a conservação da identidade cultural de uma nação, bem como servir de apoio para outras disciplinas que formam o sistema educativo brasileiro (TELIZ, 2012).

A música pode ser apresentada e manifestada de diversas maneiras, sendo uma delas por meio do canto coral, que é constituído por um grupo de pessoas, que juntos cantam e distribuem as vozes para entoar uma melodia musical (SILVA, 2014). O ato de cantar no coral remete a criança ao prestígio e reconhecimento em poder compartilhar canções para outras pessoas, como demonstrado no trecho a seguir:

Também podemos cantar em bons momentos para outras pessoas [...]. Ser conbecido por outras pessoas e cantar para elas é muito legal [...]. (Lá) 
A música e seus benefícios para o desenvolvimento saudável na infância

De acordo com Jesus e Lempke (2016), as interações desempenham um papel importante no desenvolvimento integral e social do ser humano, influenciando-os desde os primeiros anos de vida, assimilando e aprendendo a controlar suas emoções de acordo com suas vivências, favorecendo os relacionamentos sociais.

A superação de limites é como a resiliência, capacidade de se superar frente à limitação (SCHIAVO, 2014), sendo assim, as crianças podem vencer obstáculos importantes, como a timidez e também a insegurança frente ao público, por meio do canto coral:

Porque quando a gente vai cantar no coral, fazer apresentações, temos que ficar na frente de todo mundo, bom, eu tinha vergonha até de ler na sala de aula, agora perdi isso. (Ré)

Fui perdendo minha vergonha aos poucos, indo em lugares diferentes para cantar. (Sol Sustenido)

Se a gente for cantar na frente do público, temos vergonba, e podemos enfrentar isso no coral e vencer a nossa timidez: (Sol)

A música também potencializa a expressividade emocional do ser, facilitando a comunicação e a relação interpessoal, promovendo ainda acolhimento e o estabelecimento de relações e vínculos, aumentando a autoestima e proporcionando conforto e bem-estar (ZANETTINI et al., 2015), o que também ficou evidente nos relatos dos participantes deste estudo:

Eu me sinto especial cantando no coral porque vou cantar em muitos lugares e as pessoas me aplaudem. (Clave de Sol)

No coral eu fiz muitas amizades legais e isso é bom demais! (Fá)

Eu tenho bastante amigos no coral e eu gosto muito deles e da professora. (Ré)

Educadores como Villa-Lobos (1937), Mário de Andrade (1937) e Ribas (1957), entre outros, também usaram a música como instrumento facilitador da aprendizagem e estimulante da autoestima da criança e, também, no processo de socialização (MENDONA; ESTEVES, 2009). A música tem um papel relevante para a formação de laços de amizades entre o público infantil.

Ao serem questionadas sobre os motivos que as fazem participar do canto coral, algumas crianças revelaram que optaram em participar das atividades porque não tinham nada para fazer em casa: 
A música e seus benefícios para o desenvolvimento saudável na infância

Eu entrei porque não tinha nada pra fazer em casa, como minha mãe não gostava que eu ficava em casa parada, só assistindo TV e mexendo no celular, mandou eu começar a fazer coral, ai eu comecei e nunca mais parei. (Sol sustenido)

Para o crescimento saudável da criança, é importante obter formas de lazer, pois segundo Rodrigues (2011), as crianças que têm contato com a música logo cedo, aprendem a conviver melhor com os pais, com a sociedade e com outras crianças, desenvolvendo maior senso de colaboração e respeito mútuo, proporcionando maior confiança e segurança emocional, pois com a prática da música é possível liberar suas angústias e sentimentos. Finger et al. (2016), relatam que a música é considerada um elemento que enriquece o desenvolvimento humano, proporcionando bem-estar, o que auxilia em outras áreas necessárias para uma formação plena do indivíduo, como autoestima, autoconhecimento, expressão, equilíbrio e integração social.

Algumas crianças ainda afirmaram que ingressaram no coral, no primeiro momento, porque sabiam que ganhariam moletom, camisetas, como parte do uniforme:

Primeiro, eu entrei porque en queria ganhar aqueles moletons bonitos do coral... logo que eu entrei, já ganhei o meu e depois, gostei e nunca mais sai porque eu gosto de cantar e isso me faz bem! (Dó)

Os participantes do coral eram em sua maioria carentes em diversos aspectos, como socioeconômicos e culturais. Ao ingressarem no coral, os participantes recebiam um uniforme para ser usado nas apresentações e cantavam em diversos locais do município e região, sendo um incentivo para que as crianças continuassem participando ativamente.

As crianças também compartilharam que um dos motivos que as fizeram ingressar no coral foi o fato de gostarem de música e ainda, que passaram a integrar o coral porque algum familiar já havia participado:

Eu gosto de música e por isso, entrei no coral.... e dai eu comecei a me interessar mais por música e cantar. (Lá)

Antes eu traz̧ia minha irmã pra fažer coral, en ficava sentada e via vocês cantar, até que um dia eu resolvi entrar, comecei a fazer e gostei. (Clave de Sol) Ano passado, o meu irmão veio fazer o coral, dai eu vim, e comecei a cantar e gostei...(Si) 
A música e seus benefícios para o desenvolvimento saudável na infância

Por meio das atividades do coral, as crianças tiveram a oportunidade de aprender música e realizar uma atividade diferenciada, sem nenhum ônus, proporcionando também aproximação da família, com irmãos cantando juntos e pais prestigiando seus filhos nas apresentações na escola e em outros locais do município. Assim, pode-se afirmar que a música desperta múltiplos sentimentos e emoções em quem está ouvindo, promovendo a saúde para além dos horizontes da escola (FINGER et al., 2016).

As crianças ainda revelaram que participavam do coral porque gostavam das músicas que eram entoadas:

Eu gosto das músicas... (Fá)

Eu continuo vindo no coral porque é bem legal e eu amo as músicas que aprendo lá (Ré)

Não apenas a música, mas a sua própria letra também pode ser um instrumento para a promoção da saúde, estimulando o autocuidado e o pensamento reflexivo sobre ações em relação à saúde, tanto na infância e adolescência, como também para outros públicos, de diferentes faixas etárias (FINGER et al., 2016). Desta forma, a letra das músicas caracteriza-se como uma ferramenta que pode ser utilizada não apenas pela enfermagem, mas também por tantos outros profissionais da área da saúde, a fim de trazer reflexões sobre o viver saudável na sociedade.

A participação das crianças no coral pôde ampliar o conhecimento cultural, pois no coral conheceram vários ritmos musicais como samba, músicas gaúchas, músicas dos anos 90 e pop rock. De acordo com Queiroz (2004), a música, pensada em relação à cultura, poderia ser considerada como um veículo "universal" de comunicação, no sentido de que não se tem notícia de nenhum grupo cultural que não utilize a música como meio de expressão e comunicação.

Outro fator que as fazem participar do coral é a convivência com os colegas e também com as professoras:

Eu gosto dos mens colegas e das professoras do coral e de conviver com tudo isso...

Eu vou no coral porque é bem legal e tem as professoras que são bem legais e meus amigos também. (Sol) 
Com a realização do coral, os participantes se sentiam amados e respeitados pelos professores da escola e do coral, pois este era um meio de dar visibilidade para a escola, evidenciando também um vínculo saudável entre a criança e a equipe responsável, sendo que esta demonstração de afeto também envolve o crescimento saudável da criança.

A criança no coral tem a oportunidade de conviver com os colegas do grupo e Pimentel et al. (2012), destacam que o fazer musical em conjunto promove a convivência, o sentido de empatia, a ordem e a harmonia em sociedade e o aprimoramento de faculdades emocionais e mentais. Também o sentido de coletividade, e não apenas este, mas sua ideia atrelada à importância de pertencer a um grupo, cada qual com funções e características próprias e individuais.

De acordo com Souza e Atauri (2009), a música pode ser utilizada como recurso para o desenvolvimento do ser humano, da sociedade e das relações interpessoais, da criação de relações de pertencimento através da convivência coletiva, caminhando assim para a autonomia e emancipação dos indivíduos. Por ser de absoluta riqueza cultural e social, a música é ainda uma forma de lazer, de extrema importância para as crianças.

Vale ressaltar que a PNPS (BRASIL, 2010) propõe algumas estratégias para sua implementação na rede de atenção à saúde, a fim de efetivar seus objetivos. Uma das estratégias está voltada a inserção de ações de comunicação social, por meio de atividades inovadoras que fazem uso da linguagem cultural, como teatro e música. Neste sentido, a utilização da música na infância desponta como uma via de acesso à promoção da saúde, que integra novas perspectivas no âmbito da ciência, das políticas de saúde e dos programas de educação escolar, surgindo como uma possibilidade de crescimento e evolução de uma sociedade.

Ainda este estudo revela a importância da comunicação efetiva entre o ensino, pesquisa e extensão, que compõem o tripé da educação universitária, tratando-se do resultado dessa inter-relação, pois este estudo nasceu somente após os resultados positivos das ações extensionistas na comunidade, trazendo experiências e crescimento para os estudantes envolvidos no processo de ensino, extensão e pesquisa. Conforme Gonçalves (2015) aponta que entre o ensino, a pesquisa e a extensão há uma indissociabilidade, os três pilares estão em conjunto na formação profissional, sendo meios de expandir o conhecimento para toda sociedade e um ponto enriquecedor das universidades.

Como limitações do estudo pode-se citar a timidez de algumas crianças ao se depararem com o gravador, visto que perante o público nas apresentações não demonstravam tal atitude, mas foi possível contornar a situação ao buscar dialogar com naturalidade durante o 
GF. Outro fator limitante a salientar se refere à própria ação do canto coral, que exige uma equipe qualificada, com entendimento musical, tornando tal prática um desafio para os profissionais da área da saúde, necessitando de ações intersetoriais na sociedade para assim poder organizar o canto coral em diversos espaços na sociedade, a fim de ampliar as possibilidades de promover saúde na comunidade.

\section{CONSIDERAÇÕES FINAIS}

Para as crianças que participaram deste estudo, a música proporciona alegria, diversão e saúde. A prática do canto coral, além de conceder momentos de diversão, lazer e cultura, também é uma maneira de vencer os medos e a timidez das crianças. É um meio de integração, descoberta de novas amizades, de conhecer músicas interessantes, de ganhar uniformes, sendo um dos motivos que as crianças alegaram para se despertar para integrar o canto coral.

Além dos benefícios sociais e culturais, a música pode ser utilizada de maneira a promover a saúde física e mental, contribuindo para o desenvolvimento integral e saudável das crianças, de uma forma inclusiva. Assim, a música surge como um diferencial para se trabalhar com promoção da saúde não apenas na infância, mas em outras fases da vida, sendo uma ferramenta eficaz para a enfermagem.

Com a prática do canto coral, é possível proporcionar crescimento em múltiplas esferas do desenvolvimento humano, ampliando as perspectivas de abrangência social e individual e, como consequência, promovendo a saúde de todos os integrantes em nível individual e coletivo. Também ficou evidente que por meio de um projeto de extensão, muitas pesquisas poderão nascer, a fim de analisar as ações realizadas na comunidade, proporcionando aos acadêmicos envolvidos a oportunidade de aprimorar o conhecimento científico e entrelaçar o ensino, a pesquisa e a extensão.

Sugerem-se novas pesquisas enfocando a música como promotora da saúde, principalmente devido à carência de publicações, que além de serem escassas, em sua maioria, destacam a música na recuperação da saúde para aliviar dores, stress, sendo necessário estudar novas facetas do envolvimento e possibilidades da música como uma tecnologia de atuação no setor saúde. 
A música e seus benefícios para o desenvolvimento saudável na infância

\section{REFERÊNCIAS}

AREIAS, José Carlos. A música, a saúde e o bem estar. Nascer e Crescer, v. 25, n. 1, p. 7-10, 2016. Disponível em http://www.scielo.mec.pt/scielo.php?script $=$ sci arttext\&pid=S087207542016000100001. Acesso em: 15 set. 2017.

BACKES, Dirce Stein et al. Grupo focal como técnica de coleta e análise de dados em pesquisas qualitativas. $\mathbf{O}$ mundo da saúde, v. 35, n. 4, p. 438-42, 2011. Disponível em: http://www.saocamilo-sp.br/pdf/mundo saude/88/10 GrupoFocal.pdf. Acesso em 04 jun. 2018.

BARDIN, L. Análise de conteúdo. Lisboa, Portugal; Edições 70, LDA, 2011.

BERNART, Aline; ZANARDO, Vivian P. Skzypek. Educação nutricional para crianças em escolas públicas de Erechim/RS. Vivências: revista eletrônica de Extensão da Universidade Regional Integrada, v.7, n13, p. 71-79, 2011. Disponível em: http://www.reitoria.uri.br/ vivencias/Numero 013/artigos/artigos vivencias 13/n13 09.pd f. Acesso em 3 jul. 2018.

BEZERRA, Itala Maria Pinheiro; SORPRESO, Isabel Cristina Esposito. Concepts and movements in health promotion to guide educational practices. Journal of Human Growth and Development, v. 26, n. 1, p. 11-20, 2016. Disponível em: http://www.revistas.usp.br/jhgd/article/view/113709. Acesso em 04 jul. 2018.

Brasil. Ministério da Saúde. Secretaria de Vigilância em Saúde. Secretaria de Atenção à Saúde. Política Nacional de Promoção da Saúde/Ministério da Saúde, Secretaria de Vigilância em Saúde, Secretaria de Atenção à Saúde. 3. ed. Brasília : Ministério da Saúde, 2010. Disponível em:http://bvsms.saude.gov.br/bvs/publicacoes/politica nacional promocao saude 3ed.pdf Acesso em 17 ago. 2019.

CARMINATTI, Juliana da Silva; KRUG, Jefferson Silva. A prática de canto coral e o desenvolvimento de habilidades sociais. Pensamiento psicológico, v. 7, n. 14, 2010. Disponível

emhttp://portalesn2.puj.edu.co/javevirtualoj/index.php/pensamientopsicologico/article/view $\angle 134$. Acesso em 07 ago. 2017.

COMIN, Fabio Scorsolini; SANTOS, Manoel Antônio dos. O estudo científico da felicidade e a promoção da saúde: revisão integrativa da literatura. Rev. Latino-am. Enfermagem, [s.l.], v. 18, n. 3, p.188-195, maio 2010. Disponível em: http://www.scielo.br/pdf/rlae/v18n3/pt 25.pdf . Acesso em: 03 jul. 2018.

FINGER, Denise et al. Cantando e encantando: uma experiência de promoção da saúde através da música. Anais do Sepe- Seminário de Ensino, Pesquisa e Extensão: V SEPE, Chapecó, v. 5, n. 1, p.1-2, out. 2015. Acesso em: 04 jul. 2018.

FINGER, Denise. et al. Atuação da música no desenvolvimento saudável de crianças e adolescentes. Rev. Ciênc. Ext. v.12, n.2, p.106-115, 2016. Disponível em: http://ojs.unesp.br/index.php/revista proex/article/view/1316/1236 . Acesso em 04 jul. 2018. 
GONÇALVES, Nadia Gaiofatto. Indissociabilidade entre Ensino, Pesquisa e Extensão: um princípio necessário. Perspectiva, v. 33, n. 3, p. 1229-1256, 2015. Disponível em: https://periodicos.ufsc.br/index.php/perspectiva/article/view/2175795X.2015v33n3p1229/p dfa. Acesso em 17 ago. 2019.

HEIDEMANN, Buss et al. Promoção da saúde e qualidade de vida: concepções da carta de ottawa em produção científica. Ciência, Cuidado e Saúde, v. 11, n. 3, 2012. Disponível em: https://edisciplinas.usp.br/pluginfile.php/313816/mod_resource/content $/ 2 / 2012 \% 20 \mathrm{PRO}$ MOC $\%$ CC $\%$ A7A $\%$ CC $\% 83$ O $\% 20 D A \% 20 S A U \% C C \% 81 D E \% 20 E \% 20 Q U A L I D A D E \% 20 D$ E\%20VIDA.pdf. Acesso em 17 ago. 2019.

JESUS, Rosana Maria de; LEMPKE, Natália Nunes Scoralick. Manifestações emocionais das crianças na educação infantil. SYNTHESIS| Revistal Digital FAPAM, v. 6, n. 6, p. 309-325, 2016. Disponível em: http://periodicos.fapam.edu.br/index.php/synthesis/article/view/120. Acesso em 23 set. 2017.

LAZARI, Táciane Ávila; et. al. 2012, Londrina. Enigmas da dor: Ação multiprofissional em saúde. VI Congresso Multiprofissional em Saúde, Londrina: Edunifil, 2012. 248 p. Disponível em: $\quad$ http://unifil.br/portal/images/pdf/documentos/anais/congressomultiprofissional/vi-congresso.pdf\#page $=101$. Acesso em: 03 jul. 2018.

MENDONÇA, Inês; ESTEVES, Maria Lapa. Impacto da música na criação de laços de amizade em crianças. International Journal of Developmental and Educational Psychology, v. 1, n. 1, p. 109-117, 2009. Disponível em: http://www.redalyc.org/pdf/3498/349832320011.pdf . Acesso em 19 set. 2017.

OLIVEIRA, Marilise Fátima de et al. Musicoterapia como ferramenta terapêutica no setor da saúde: Uma revisão sistemática.. Revista da Universidade Vale do Rio Verde, v. 12, n. 2, p. 871-879, 2014. Disponível em: http://periodicos.unincor.br/index.php/revistaunincor/article/view/1739. Acesso em 10 set. 2017.

OTTAWA, A. CARTA DE. A Promoção da Saúde. In: $1^{\mathbf{a}}$ Conferência Internacional, Canadá. 1986. p. 17-21. Disponível em: http://www.iasaude.pt/attachments/article/152/Carta de Otawa Nov 1986.pdf. Acesso em 17 ago. 2019.

PEREIRA, Mauricio Gomes. Epidemiologia: Teoria e prática. Rio de Janeiro: Guanabara Koogan, 2008.

PIMENTEL, Carlos Eduardo et al. Evidências de validade e precisão da Escala de Coping através de Ouvir Música. Psico-USF, v. 17, n. 1, p. 141-151, 2012. Disponível em http://www.redalyc.org/pdf/4010/401036088015.pdf . Acesso em 10 set. 2017.

PRAZERES, Maria Márcia Viana et al. O Canto como Sopro da Vida: um estudo dos efeitos do Canto Coral em um grupo de coralistas idosas. Revista Kairós: Gerontologia, v. 16, n. 4, p. 2013. 175-193, Disponível em: https://revistas.pucsp.br/index.php/kairos/article/view/19636 . Acesso em 07 ago. 2017.

QUEIROZ, Luis Ricardo Silva. Educação musical e cultura: singularidade e pluralidade cultural no ensino e aprendizagem da música. Revista da ABEM, v. 12, n. 10, 2014. 
A música e seus benefícios para o desenvolvimento saudável na infância

Disponível

em:http://www.abemeducacaomusical.com.br/revistas/revistaabem/index.php/revistaabe $\mathrm{m} /$ article/view/367. Acesso em 03 jul. 2018.

RODRIGUES, Carmen Aguera Munhoz; ROSIN, Sheila Maria. A importância do ensino de música para o desenvolvimento infantil. 22 f. Trabalho de Conclusão de Curso (Graduação em Pedagogia) - Universidade Estadual de Maringá, Cianorte, 2011. Disponível em: https://s3.amazonaws.com/academia.edu.documents/39428412/a importancia de ensinar musica.pdf?AWSAccessKeyId=AKIAIWOWYYGZ2Y53UL3A\&Expires=1540762825\&Signa ture $=\mathrm{R} \% 2 \mathrm{FT} 1 \mathrm{Qdl} 3 \mathrm{apFOf29oq} 9 \mathrm{xckCQbkb4} \% 3 \mathrm{D} \&$ response-content-

disposition $=$ inline $\% 3 \mathrm{~B} \% 20$ filename $\% 3 \mathrm{DA}$ importancia de ensinar musica.pdf . Acesso em 4 jul. 2018.

ROVIDA, Tânia Adas Saliba; et. al. O conceito de saúde geral e bucal na visão dos cuidadores de idosos. Odontol. Clín.-Cient. 2013, vol.12, n.1, pp. 43-46. Disponível em: http://revodonto.bvsalud.org/pdf/occ/v12n1/a10v12n1.pdf . Acesso em: 03 jul. 2018.

SCHIAVO, Sueli Ferreira. Desafios à infância: vínculos comunicacionais, mídia e resiliência. In: Congresso Internacional Comunicação e Consumo-Comunicon, 2014. Disponível em:

http://www3.espm.br/download/Anais Comunicon 2014/gts/gttres/GT03 Sueli SCHIAV O.pdf.Acesso em: 23 set. 2017.

SILVA, Ana Maris Goulart. O sujeito cantante: reflexões sobre o canto coral [Dissertação]. Faculdade de Educação da Universidade de São Paulo, 2014. Disponível em: https://www.teses.usp.br/teses/disponiveis/48/48134/tde-08122014145737/publico/ANA MARIS GOULART SILVA.pdf. Acesso em: 15 fev. 2019.

SOUZA, Roberta Maia de; ATAURI, Ilda Chicalé. A música como instrumento de direitos sociais. Revista do Instituto de Pesquisas e Estudos: Construindo o Serviço Social, v. 13, n. 23, 2009. Disponível em: http://moodle.ite.edu.br/ojs/index.php/css/article/view/89 . Acesso em 19 set. 2017.

TAETS, Gunnar Glauco de Cunto; BARCELLOS, Lia Rejane Mendes. Música no cotidiano de cuidar: um recurso terapêutico para enfermagem. Revista de Pesquisa Cuidado é Fundamental Online, v. 2, n. 3, 2010. Disponível em: http://www.redalyc.org/html/5057/505750832014/. Acesso em 16 set. 2017.

TELIZ, Marco Andree Morel. Educação musical e promoção da saúde: uma proposta de leitura interdisciplinar. 2012. Disponível em: http://www.bibliotecadigital.ufmg.br/dspace/handle/1843/AAGS-984NDC. Acesso em: 16 set. 2017.

VENANCIO, Tatiana. Desvendando os mecanismos do prazer de ouvir música. Ciência e Cultura, v. 66, n. 3, p. 64-65, 2014. Disponível em: http://cienciaecultura.bvs.br/scielo.php?pid=S0009-

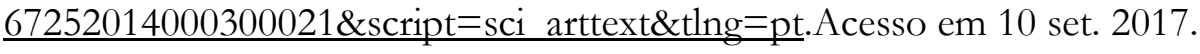

ZANETTINI, Angélica et al. Quem canta seus males espanta: um relato de experiência sobre o uso da música como ferramenta de atuação na promoção da saúde da criança. Revista 
A música e seus benefícios para o desenvolvimento saudável na infância

Mineira de Enfermagem, v. 19, n. 4, p. 1060-1069, 2015. Disponível em: http://www.reme.org.br/artigo/detalhes/1058 . Acesso em 10 set. 2017.

Recebido em: 28/10/2018

Aceito em: 16/09/2019 